\title{
The Comparison of the Emotional States of the Cancer Children to their Healthy Peers
}

\author{
Lugen Ceren Kiyan and Ender Durualp*
}

\author{
Department of Child Development, Faculty of Health Sciences, Ankara University, Ankara, Turkey
}

\begin{abstract}
This study aimed to compare the emotional status of children with cancer between the ages of five and twelve with their healthy peers. The study groups of the research consist of children with cancer disease between the ages of five and twelve which have inpatient treatment at pediatric oncology service and healthy peers of the same age and gender. Totally 70 children, with 35 cancer who took inpatient treatment and two or more chemotherapy treatments between the dates September-November 2017, and also whose families accepted to participate in the research and 35 healthy children who live at the centre of Ankara, and were chosen with easy sampling method were included to the research. When collecting the data, "General Information Form" was used to determine the sociodemographic characteristics of the children and their families and the pictures drawn by the children were used to determine the emotional situations of the children. Pictures were evaluated according to the expert opinions using Koppitz's "Draw a Man" evaluation test. The Chi-Square test was used to evaluate the data. The coherence between the experts was determined by the Cronbach Alpha value which was found 0.83 . According to findings of the research, it was concluded that the impulsiveness, self-insecurity, anxiety, and anger-aggressiveness ( $p>0.05)$; shyness-timidity $(p<0.05)$ of children with cancer was significantly higher than their healthy peers.
\end{abstract}

Keywords: Child, Cancer, Emotional Status, Painting, Koppitz.

\section{INTRODUCTION}

Cancer is a kind of illness terminating the tissues and occurring with abnormal cell reproduction. General incidence of cancers in childhood age changes between 50 and 200 per million all over the world. Approximately 300.000 children are diagnosed with cancer every year. More than $80 \%$ of the cancer children could survive thanks to access to qualified service and sustain a complete and healthy life [1]. However; the diagnosis of cancer is a traumatic phenomenon causing to serious losses in the lives of the children. The fact that it is a medical-physical illness and survival period increases cause too many problems in mental and psycho-social aspects and bring about psychological disorders [2]. It is stated in the conducted studies that psychological disorders such as aggression, anxiety, and depression are observed in higher ratios in the patient children when compared to the healthy children [3-10].

These children are in the situation, illness and hospital stay, Children's communication with health personnel and medical procedures applied to the child in the mental state of the temporary or permanent causes some temporary effects [11]. The degree of the vulnerability of the child from the illness and the state of staying in hospital, changes depending on the age, cognitive development level, period and type of the

*Address correspondence to this author at the Department of Child Development, Ankara University Faculty of Health Sciences, Altındag/Ankara, Turkey; Tel: +903123191450; E-mail: endora2212@hotmail.com illness, period of remaining in hospital, previous experiences, preparation for the state of staying in hospital, attitude of the family and cultural properties. It is very valuable to assess and consider the psychosocial states of the children depending on the increase in the number of cancer children and the elongation of the life cycle [12]. In children who have a long-term illness and have to lie in hospital, fear, anxiety, phobia, regression (backward), introversion, depression, frustration, aggression can occur [13]. It is very important to understand the emotional state of the child because of the negative situation in the child's illness and illness. The painting, which is a more powerful expression tool than words at a young age, gives us important information about the child's inner world and the process of growth [14]. One of the tools working for the recognition of the child and used for establishing communication with the children whose social adaptation problems are observed and who have got long-term illnesses is art. Art is the reflection of the feelings and ideas of the child $[15,16]$. The use of projective techniques such as art which is both verbal and not verbal is suggested in the assessment of the psycho-social state. Especially the children in preschool and school periods could express their feelings and ideas with pictures rather than words $[14,17]$.

It is essential to use the picture as the assessment tool in the periods in which children have hardships in speaking and expressing their feelings $[18,19]$. Within this context; child picture is an efficient method in the evaluation of the emotional states of the patient children because it reflects the problems and 
disturbances they are in $[20,21]$. Various drawing characteristics such as excessive or deficient drawing of body parts, disjointed body parts with no connection to each other, disproportion regarding the length of the figures and the exaggerated reflection of the normal appearance have been encountered when compared to the drawings of other children in the same age group in the pictures of the patient children in the conducted studies $[15,22]$. It is also specified that the emotional states of the children are determined even with the pictures drawn by the children, drawing pictures increases the communication skills of the children, improve their perceptions and reflect their feelings [5, 7]. The assessment of the emotional states in especially cancer children is important and necessary in terms of establishing healthy communication with child and planning the approach to the child. Within this direction; in the study, it has been aimed to compare the emotional states of the children between the range 5-12 ages having cancer and are inpatient to their healthy peers, such as impulsiveness, insecurity, introversion, and anger.

\section{MATERIAL AND METHODS}

\section{Model of the Study}

The study has been conducted as descriptive research to compare the emotional states of the inpatient cancer children between the ages 5-12 to their healthy peers.

\section{The Working Group of the Study}

The cancer children whose ages are between 5-12 and who are inpatient in the paediatric oncology service of a university hospital have been included in the study. Children with cancer are not classified according to the types of cancer. Comparison group consists of their healthy peers at the same age, gender and number. The children to be taken to the comparison group have been selected with a convenience sampling method after the determination of the age, gender and number of the cancer children. Within this direction; totally 70 children as 35 cancer children who are inpatient in the paediatric oncology service, treated with two or more chemotherapies, with no major development disorder and who and whose family have accepted to participate in the study and as 35 healthy children selected with convenience sampling method and within the same age and gender with the cancer children have been included in the study group of the research.

\section{Data Collection Tools}

The data of the study have been collected by using "General Information Form", "Draw A Man" test of Koppitz and the pictures drawn by the children.

The questions such as the age, gender, birth order, brother number, class, illness diagnosis, diagnosis age, hospital stay duration and family type of the child and the age, education status, profession, working status, status of being alive-dead, income state etc. of the parents take place in the General Information Form.

Human Figure Drawing Assessment of Koppitz is used to determine the emotional states of the children between the ages 5-12. Koppitz has examined the human figure drawings of the children to be able to assess their emotional states. In his studies, he has benefited from items with clinical validity taking place in "Draw A Man" test. The items belonging to the emotional development have clinical validity, and the test consists of 28 items. These items are collected under five dimensions as impulsivity, feeling of insecurity/insufficiency, worry, shyness and anger and they are scored as "yes" or "no" depending on the picture drawn by the child $[23,24]$.

\section{Ethical Dimension of the Study}

The written permits necessary from the university hospital have been taken before the study. All the children and their parents included in the study have been met, the time has been spent with them, communication has been established and the child and the parents have been comforted. The purpose and method of the study have been explained and cooperation has been made. Verbal and written information has been given to the children, and their parents in the issue of the study and their approvals have been taken before the collection of the data.

\section{Data Collection Method}

The purpose of the study has been cited to the parents, and General Information Form has been applied to those who have accepted with the face-toface interview technique. Afterwards, the materials required for children to draw (A4 paper, 12 colour paint pen, pencil and eraser) "I want you to draw a picture of a person who has everything." they were asked to draw a human figure by giving the directive. The duration of the child's formal drawing was about 15-30 minutes, although it was due to factors such as age, developmental level, psychological state, physical 
environment, type of cancer and the side effects of the treatment during the formal drawing, the number of days of hospitalisation. With the same method, necessary materials have been given to the healthy children included in the comparison group and they have also been requested to draw a human figure, and General Information Form has been applied to the parents. The data of the study have been collected in September-December 2017. The pictures of the children included in the study were evaluated by three experts who had taken the Koppitz Human Drawing Test and could assess the images.

\section{Assessment and Analysis of the Data}

The emotional states of the children have been determined after the experts have assessed the pictures drawn by them according to the assessment criteria of Koppitz. The attained data have been analysed with the Chi-Square test. Cronbach's Alpha value has been considered for the consistency among the experts assessing the pictures drawn by the children, and it has been found 0.833. $p<0.05$ values have been accepted as meaningful in all the analyses.

\section{FINDINGS}

"General Information Form" applied to the children and their parents included in the study have been assessed and the socio-demographic properties belonging to the children, and their parents have been presented in tables.

It has been determined that $42.8 \%$ of the healthy children are between the ages $8-10,62.9 \%$ of them are male, $71.4 \%$ of them are the first child, $80 \%$ of them have $1-3$ brothers, $82.9 \%$ of them go to school and $65.8 \%$ of them have outstanding academic success. $40 \%$ of the cancer children are between the ages $8-10$, 62.95 of them are male, $37.1 \%$ of them continue their education in the hospital with bedside support or at home with teacher support and $60 \%$ of them have outstanding academic success (Table 1). It has been detected that the age average of the healthy children is $111.82 \pm 29.45$ months and the age average of the cancer children is $113.68 \pm 29.48$ months. It has also been determined that the majority of the children live in an apartment building in the metropolis and they do not have any physical disability.

Table 1: Distributions of some Properties Belonging to the Children Included in the Study

\begin{tabular}{|c|c|c|c|c|}
\hline \multirow{2}{*}{ FEATURE } & \multicolumn{2}{|c|}{ Healthy Children } & \multicolumn{2}{|c|}{ Children With Cancer } \\
\hline & $\mathrm{n}$ & $\%$ & $\mathbf{n}$ & $\%$ \\
\hline \multicolumn{5}{|l|}{ Age } \\
\hline $5-7$ years & 10 & 28.6 & 10 & 28.5 \\
\hline $8-10$ years & 15 & 42.8 & 14 & 40 \\
\hline $11-12$ years & 10 & 28.6 & 11 & 31.5 \\
\hline \multicolumn{5}{|l|}{ Gender } \\
\hline Girl & 13 & 37.1 & 13 & 37.1 \\
\hline Boy & 22 & 62.9 & 22 & 62.9 \\
\hline \multicolumn{5}{|l|}{ Birth Order } \\
\hline First Child & 25 & 71.4 & 10 & 28.6 \\
\hline Middle Child & 1 & 2.9 & 12 & 34.3 \\
\hline Last Child & 9 & 25.7 & 13 & 37.1 \\
\hline \multicolumn{5}{|l|}{ Number of Siblings } \\
\hline Only Child & 7 & 20 & 3 & 8.6 \\
\hline 1-3 siblings & 28 & 80 & 25 & 71.4 \\
\hline 4 and above & - & - & 7 & 20 \\
\hline \multicolumn{5}{|l|}{ Education Status } \\
\hline Go to Kindergarten & 6 & 17.1 & 5 & 14.3 \\
\hline Go to School & 29 & 82.9 & - & - \\
\hline Home Education & - & - & 30 & 85.7 \\
\hline \multicolumn{5}{|l|}{ Academic Success } \\
\hline Good & 6 & 17.1 & 6 & 17.1 \\
\hline Very good & 23 & 65.8 & 21 & 60 \\
\hline Go to Kindergarten & 6 & 17.1 & 8 & 22.9 \\
\hline
\end{tabular}


Table 2: Distribution of some Properties Belonging to the Parents of the Children Included in the Study

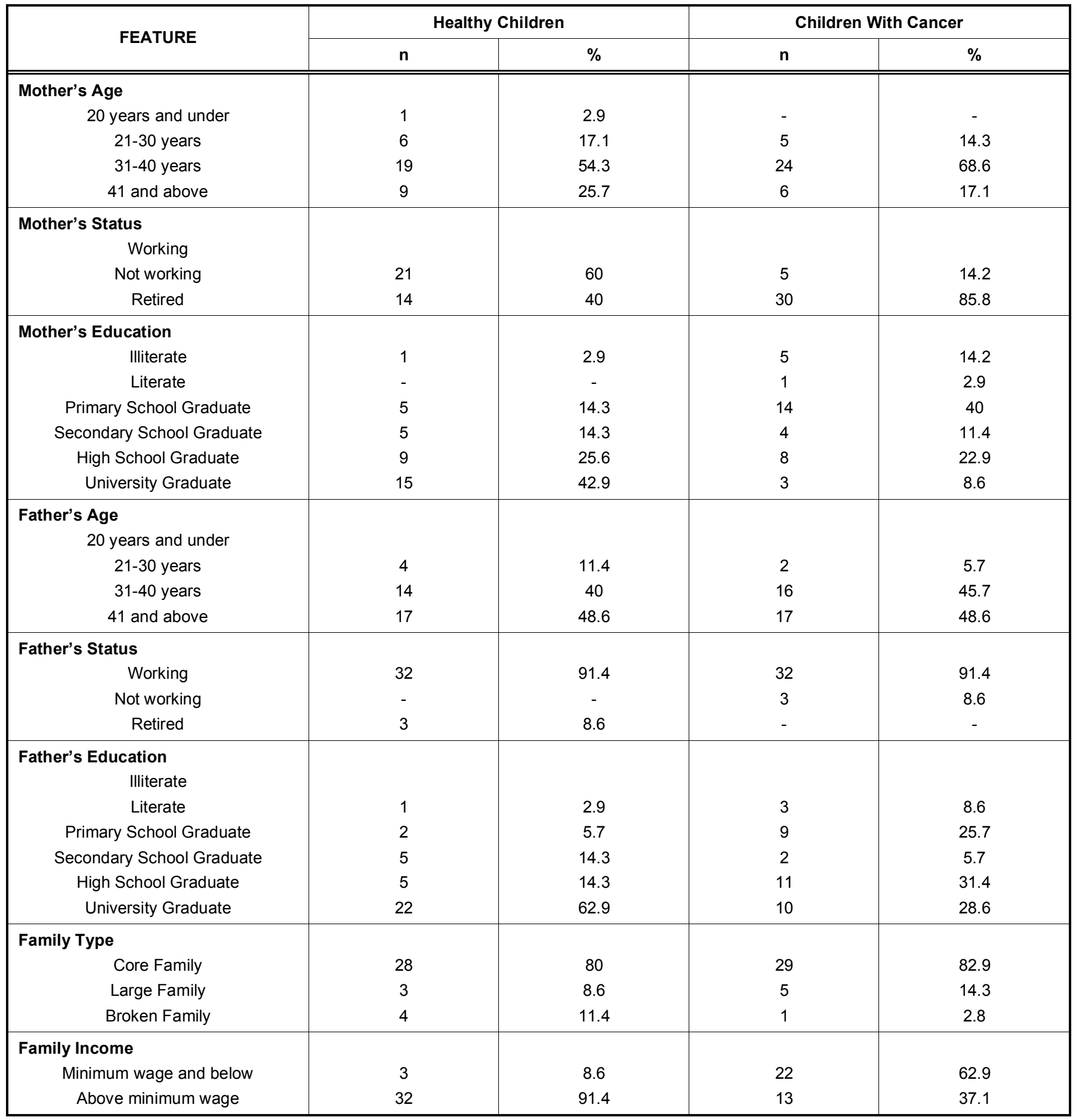

It has been determined that $80 \%$ of the healthy children live in nuclear family, the individual number in the family of $88.6 \%$ of them is between $2-4$, the families of $91.4 \%$ of them have an income above the minimum wage and $68.6 \%$ of them perceive the income level of their family as in the medium level, the ages of $54.3 \%$ of their mothers are between $31-40,60 \%$ of them work and $42.9 \%$ of them have graduated from university and
$48.6 \%$ of their fathers are at the age of 41 and above, $91.4 \%$ of them work and $62.9 \%$ of them have graduated from university. $82.9 \%$ of the cancer children live in nuclear family, the individual number in the family of $68.6 \%$ of them is between $3-5$, the families of $62.9 \%$ of them have an income at and below the minimum wage and $60 \%$ of them perceive the income level of their family as in the low level, the ages of 
Table 3: Distribution of some Properties Belonging to the Illnesses of the Cancer Children Included in the Study

\begin{tabular}{|c|c|c|}
\hline FEATURE & $\mathbf{n}$ & $\%$ \\
\hline \multicolumn{3}{|l|}{ Age of Diagnosis } \\
\hline 3-6 years & 12 & 34.2 \\
\hline $7-10$ years & 17 & 48.6 \\
\hline $11-12$ years & 6 & 17.2 \\
\hline \multicolumn{3}{|l|}{ The Time of Diagnosis } \\
\hline $12-25$ months & 11 & 31.4 \\
\hline $26-37$ months & 5 & 14.4 \\
\hline 38 months and above & 3 & 8.4 \\
\hline \multicolumn{3}{|l|}{ Frequency of Hospitalization } \\
\hline $1-5$ times & 14 & 40 \\
\hline \multicolumn{3}{|l|}{ Last Day at the Hospital } \\
\hline $5-10$ days & 15 & 42.8 \\
\hline $11-25$ days & 8 & 23 \\
\hline Over 25 days & 12 & 34.2 \\
\hline \multicolumn{3}{|l|}{ Illness Posibility of Other Siblings } \\
\hline Yes & 1 & 2.9 \\
\hline No & 34 & 97.1 \\
\hline \multicolumn{3}{|l|}{ The Presence of Alopecia } \\
\hline Yes & 27 & 77.2 \\
\hline No & 8 & 22.8 \\
\hline
\end{tabular}

$68.6 \%$ of their mothers are between $31-40,82.9 \%$ of them do not work and $40 \%$ of them have graduated from primary school and $48.6 \%$ of their fathers are at the age of 41 and above, $91.4 \%$ of them work and $31.4 \%$ of them have graduated from high school (Table 2).

No statistical difference could be found between the ill and healthy children taken to the study in terms of the properties such as age, gender, birth order, number of brothers, the status of going to school and academic success, the place they live, family type, income, age of parents, status of education and working $(p>0.05)$.

It has been determined that $48.6 \%$ of cancer children have been diagnosed between the ages 7-10, a period of time like 6-11 months has passed upon the diagnosis of $45.8 \%$ of them, $40 \%$ of them have stayed in hospital $1-5$ times and 16 and more times, $42.8 \%$ of them have stayed in hospital for 5-10 days, there is no illness in the brothers or sisters of $97.1 \%$ of them and the existence of alopecia has been observed in $77.2 \%$ of them (Table 3). The most frequently observed cancer types in the diagnosis of the cancer children taken to the sample are ALL and lymphoma.
The observation ratio of impulsivity out of the emotional indicators has been found as $42.9 \%$ in healthy children and as $57.1 \%$ in cancer children. It has been seen that the difference observed between healthy and cancer children is not statistically meaningful in terms of impulsivity $\left(x^{2}=1.43, s d=1\right.$, $p>0.05$ ) (Table 4). When the pictures drawn by the children have been examined, it has caught the attention that the most frequently brought items showing impulsivity are "big figure" and "the existence of no neck".

As a result of the conducted analyses, it has been found that lack of self-confidence or insufficiency is existent by $51.4 \%$ in healthy children and by $62.9 \%$ in cancer children. There is no meaningful difference between the healthy and cancer children taken to the study in terms of lack of self-confidence and insufficiency $\left(x^{2}=0.93, s d=1, p>0.05\right)$ (Table 5). When the pictures of the children have been examined, it has been observed that the most frequently used items are "the existence of no hands" and "the existence of no feet" in the drawings showing the lack of selfconfidence and insufficiency. 
Table 4: Chi-Square Results Belonging to the Impulsivity of the Children Included in the Study

\begin{tabular}{|c|c|c|c|c|c|c|c|}
\hline \multirow{2}{*}{ IMPULSIVITY } & \multicolumn{2}{|c|}{ Healthy } & \multicolumn{2}{|c|}{ With Cancer } & \multirow{2}{*}{$x^{2}$} & \multirow{2}{*}{ sd } & \multirow{2}{*}{ p } \\
\hline & $\mathbf{n}$ & $\%$ & $\mathbf{n}$ & $\%$ & & & \\
\hline YES & 15 & 42.9 & 20 & 57.1 & \multirow{2}{*}{1.43} & \multirow{2}{*}{1} & \multirow{2}{*}{0.232} \\
\hline NO & 20 & 57.1 & 15 & 42.9 & & & \\
\hline
\end{tabular}

Table 5: Chi-Square Results of the Children Included in the Study Belonging to the Lack of Self-Confidence and Insufficiency

\begin{tabular}{|c|c|c|c|c|c|c|c|}
\hline \multirow{2}{*}{$\begin{array}{l}\text { FEELING OF INSECURITYI } \\
\text { INADEQUACY }\end{array}$} & \multicolumn{2}{|c|}{ Healthy } & \multicolumn{2}{|c|}{ With Cancer } & \multirow{2}{*}{$x^{2}$} & \multirow{2}{*}{ sd } & \multirow{2}{*}{ p } \\
\hline & $\mathbf{n}$ & $\%$ & $\mathbf{n}$ & $\%$ & & & \\
\hline YES & 18 & 51.4 & 22 & 62.9 & \multirow{2}{*}{0.93} & \multirow{2}{*}{1} & \multirow{2}{*}{0.334} \\
\hline NO & 17 & 48.6 & 13 & 37.1 & & & \\
\hline
\end{tabular}

The observation ratio of the worry states of the healthy and cancer children have been found as $40 \%$ in healthy children, and as $54.3 \%$ in cancer children depending on the pictures, they have drawn. There is no statistically meaningful difference between the worries of the children and their status of being cancer or healthy $\left(x^{2}=1.43, s d=1, p>0.05\right)$ (Table 6). When the pictures of the children have been examined, it has been seen that the most frequently drawn figures showing the worry are "clouds, rain and birds flying".

The observation ratio of shyness-timidity out of the emotional indicators is $45.7 \%$ in healthy children and $80 \%$ in cancer children. It has been found that the difference observed between healthy and cancer children is meaningful in terms of shyness-timidity $\left(x^{2}=8.81, s d=1, p<0.05\right)$ (Table 7$)$. It has been detected that the items most frequently observed in the pictures of the children are "little figure (shorter than $9 \mathrm{~cm}$ )" and "the existence of no nose" out of the shyness-timidity indicators.
It has been found in the conducted analyses that the observation ratio of anger and aggression is $14.3 \%$ in healthy children and $28.6 \%$ in cancer children. It has been determined that there is no statistically meaningful difference between the anger and aggression of cancer and healthy children taken to the study $\left(x^{2}=2.12, s d=1, p>0.05\right)$ (Table 8). It has drawn the attention in the pictures of the children that "exaggerated teeth" and "big hands" have been drawn most frequently out of the anger and aggression indicators.

\section{DISCUSSION}

The observation frequency of impulsivity is higher in the cancer children $(57.1 \%)$ taken to the study when compared to healthy children $(42.9 \%)(p>0.05)$. The situation showing itself in the skills of planning the behaviours, postponing the desires and being able to stop oneself is defined as impulsivity. Children act with their impulses in the first years of their lives. Because

Table 6: Chi-Square Results Belonging to the Worries of the Children Included in the Study

\begin{tabular}{|c|c|c|c|c|c|c|}
\hline \multirow{2}{*}{ WORRIES } & \multicolumn{2}{|c|}{ Healthy } & \multicolumn{2}{c|}{ With Cancer } & \multirow{2}{*}{ X2 } & sd \\
\cline { 2 - 6 } & $\mathbf{n}$ & $\%$ & $\mathbf{n}$ & $\mathbf{p}$ & \\
\hline \hline YES & 14 & 40 & 19 & 54.3 & 1.43 & 1 \\
\hline NO & 21 & 60 & 16 & 45.7 & & 0.231 \\
\hline
\end{tabular}

Table 7: Chi-Square Results Belonging to the Shyness-Timidity of the Children Included in the Study

\begin{tabular}{|c|c|c|c|c|c|c|c|}
\hline \multirow{2}{*}{ SHYNESS/TIMIDITY } & \multicolumn{2}{|c|}{ Healthy } & \multicolumn{2}{|c|}{ With Cancer } & \multirow{2}{*}{$x^{2}$} & \multirow{2}{*}{ sd } & \multirow{2}{*}{$\mathbf{p}$} \\
\hline & $n$ & $\%$ & $n$ & $\%$ & & & \\
\hline YES & 16 & 45.7 & 28 & 80 & \multirow{2}{*}{8.81} & \multirow{2}{*}{1} & \multirow{2}{*}{0.003} \\
\hline NO & 19 & 54.3 & 7 & 20 & & & \\
\hline
\end{tabular}


Table 8: Chi-Square Results Belonging to the Anger and Aggressions of the Children Included in the Study

\begin{tabular}{|c|c|c|c|c|c|c|c|}
\hline \multirow{2}{*}{ ANGER/ AGGRESSIONS } & \multicolumn{2}{|c|}{ Healthy } & \multicolumn{2}{|c|}{ With Cancer } & \multirow{2}{*}{$x^{2}$} & \multirow{2}{*}{ sd } & \multirow{2}{*}{ p } \\
\hline & $\mathbf{n}$ & $\%$ & $\mathbf{n}$ & $\%$ & & & \\
\hline YES & 5 & 14.3 & 10 & 28.6 & \multirow{2}{*}{2.12} & \multirow{2}{*}{1} & \multirow{2}{*}{0.145} \\
\hline NO & 30 & 85.7 & 25 & 71.4 & & & \\
\hline
\end{tabular}

they are not in the conscious of being able to consider the cause-effect relations, understand the feelings of the opposite party and perceive the dimension of giving damage yet, they are insufficient in the issue of controlling their behaviours [25]. The behaviours such as addictive and passively obeying to everything and also aggressive behaviours could be seen in some children in the 6-12 age group depending on staying in hospital [2]. It could be said that the children included in the study, healthy or cancer and within the age group 5-12 act with their impulses due to their age and development properties. It has been determined by Cihangir and Kılıçarslan Törüner (2007) that the cancer children live impulsivity in higher ratios when compared to acute surgical patients and healthy children; and it has also been determined by Durualp and Altay (2012) that the cancer children between the ages 6-12 live impulsivity in higher ratios when compared to healthy children $[5,26]$. The fact that the children have hardships in controlling their behaviours, desires and feelings due to the illness and staying in the hospital is an expected situation. It is considered that the increase in the impulsivity of the cancer children may have been increased by the diagnosis of cancer, staying away from their social life, being in the hospital environment and also being in the treatment process.

The observation ratio of the lack of self-confidence and insufficiency in the cancer children taken to the study is higher than that of the healthy children $(p>0.05)$. Unaidedness and vulnerability stemming from the uncertainties related to their purposes, ideas, abilities and relations with others and occurring when faced with various problems could be defined as the feeling of the lack of self-confidence and insufficiency [27]. It observed that as the children grow up, their feelings of the lack of self-confidence and insufficiency decrease. The illness state of the children in school term prevents their participation in the group activities with their peers, and this situation causes to the feelings of anger and inhibition and also addictive [28]. The children between the ages 6-12 and with a chronic illness like cancer may have hardships in expressing their feelings. The children at these age groups could be encouraged to tell a story as well as their verbal expressions or to draw a picture and express themselves, and in this way, their reactions to stress could be efficiently assessed [2]. Based on the pictures drawn by the ill children, the fact that they experience the lack of self-confidence and insufficiency more than the healthy children has been revealed with studies [5, 26]. Boekaerts and Röder (1999) have examined the studies regarding the chronic illnesses at the age of childhood and specified that there is generally no difference in the school success, self-confidence and stress levels of the children when compared to the healthy children [29]. Children with chronic illness use various coping strategies to be able to overcome multiple diseases and common stress factors. The coping strategies they use depending on the common stress factors have similarities with those of the healthy children. In the conducted study, lack of self-confidence and insufficiency are more in the cancer children according to the pictures they have drawn. The children may turn in on themselves because the chronic illnesses like cancer require long term treatment and frequent staying in the hospital; they may not want to establish communication with the hospital personnel, their families and other people around them and may feel lack of self-confidence and insufficiency. Emotional problems could be faced as a result of the continuity of the feelings of the lack of self-confidence and insufficiency and minimisation of the communication with their environment. This mood established in the children day by day during the stay in the hospital and the treatment may prevent them from expressing themselves, transmitting their feelings and ideas to others and be able to adapt to the society. Having emotional problems as well as the diagnosis of chronic illness may wear the children more and may cause more critical issues in their future lives. Due to all these reasons, it is considered that the people in communication with the children and especially the doctors, nurses and child development specialists from the health personnel individually dealing with them during their treatment should encourage them for expressing themselves and establishing communications with the people around them.

Despite the developing technology and treatment methods, the fears and worries of the children about 
death increase as the breakthrough stages of the illness become frequent and the illness proceeds in the cancer children [30]. They are experienced more in the cancer children when compared to the healthy children according to the pictures they have drawn $(p>0.05)$. Problems such as depression, behaviour and adaptation problems, physical insufficiency and excessive worry are generally observed in the cancer children. It is seen that the anxiety levels of the school children primarily between the ages 6-12 are high and the themes such as loneliness, separation and death are mentioned in their stories. A cancer school child to see himself/herself different from his/her peers due to the changes occurring in his/her appearance and loss of function depending on the illness and the fact that his/her friends will reject s/he may cause to worry [26, 31]. In the study conducted by Giannakopoulos et al. (2009), it has been detected that the children between the ages 8-12 and having cancer treatment have very high anxiety points [6]. As a result of the study conducted by Şen Beytut et al. (2009), it has been found that the anxiety finding is higher in the pictures of the children with acute and chronic illness when compared to those of the healthy children [7]. In the study conducted by Nazari et al. (2017), it has been determined that the depression and anxiety points of the cancer children are at higher levels than those of the healthy children [9]. It has been specified by Lewis et al. (1988) that high worry levels could develop in children with chronic illness [32]. Especially the children between the ages 10-15 perceive the chronic disease as the loss of independence and termination of the plants for the future. This situation may cause the rise in worry and anxiety level [32-34].

In this study, no meaningful difference could be found between the worries of healthy and cancer children. In other words; a high-level worry may not be observed in the children who have been newly diagnosed or whose diagnosis has taken a while. It has been detected that the majority of the children brought to the study (45.8\%) were diagnosed 6-11 months ago. An extended treatment and healing process awaits the children and families. For this reason; the assessment and monitoring of the emotional states of the children are important and necessary.

Shyness-timidity from the emotional indicators are observed higher at a meaningful level in the cancer children when compared to the healthy children. School term covers the childhood period between the ages 512. Some of the properties of this period are peer togetherness and starting school. Friendship relations gain importance in childhood period and it significantly affects the social and emotional development of the child. Children start to understand the feelings of others and establish mutual social relations after the ages of 5-6. They establish a friendship relation based on help and trust at the school age. In this period in which the most important bases of socialization and freedom are laid, the diagnosis of a chronic illness in the child may cause to sudden social-emotional changes. Their experiences with their friends in their development process provide opportunities for them to gain communication and social skills. Those showing these behaviours could be assessed as more social, outgoing and sociable; and tendency to adductive and shy-timid and aggressive behaviours could be observed in the children who could not establish friendship [35]. The reasons such as the nature of cancer, long lasting diagnosis and treatment process cause the children to stay away from their peers and have communication problems, have negative friendship relations and increase the feelings of shyness-timidity. It is seen that the assessment of the social an emotional states of both healthy and ill children and supporting of the shy and timid children by the child development specialists are necessary and very important. In the study conducted by Cihangir and Kılıçarslan Törüner (2007) and Durualp and Altay (2012), it has been determined that the cancer children experience the feelings of shyness and timidity in higher ratios when compared to the healthy children and the children with acute surgical illness [5, 26].

Anger and aggression have been found higher in cancer children when compared to the healthy children. Anger or fury is defined as a basic affectivity way revealed for the purpose of protecting oneself and warning the opposite party as a result of the prevention of the injustice, inequity, desires, needs and plans and perceiving the different met situations as a threat for themselves. Aggression is the fullest extent of the reactions of a person for annihilating himself/herself or others. Individual may have aggressive and anger feelings when $\mathrm{s} /$ he has been prevented from reaching an aim or meeting a need [36]. Cancer children at school age think that having a fatal illness is injustice for themselves and may have anger. While they may passively turn in upon themselves one day, they may show overreaction the next day [31]. In the study conducted by Durualp and Altay (2012), it has been detected that the anger and aggression feelings of cancer children at the age of 6-12 are meaningfully higher than those of healthy children [5]. In the study conducted by Şen Beytut et al. (2009), the finding of 
aggression has been found higher in the pictures of the children with acute and chronic illness when compared to the pictures of the healthy children [7].

The age of diagnosis, duration of diagnosis, hospitalization periods and types of cancer are different in the study. These factors may affect the mental and emotional state of children should not be ignored. In addition, the pictures of children in the study reflect their immediate emotional state. It should not be forgotten that sudden changes may be experienced in the emotional states of the cancer children. The most important factors causing to these changes could be given sequenced as the period of hospital stay, the time they have been diagnosed and the sudden and unexpected changes in their health condition. Having the children draw pictures means helping them express their ideas. Especially the cancer children to be under risk in social and emotional terms requires the assessment and monitoring of their emotional states. It has been seen as a result of the observations conducted during the study that there are differences between the pictures they have drawn at the first day of their hospital stay and those drawn right before they have been discharged from hospital. In this respect; while the assessment of the emotional development via drawing is seen as important; on the other hand, it will be in good taste to consider that the emotional states of the children may show sudden and unexpected changes, they may be affected from various factors and they should be repeated in different times and environments.

\section{CONCLUSION AND RECOMMENDATION}

As a result of the study; it has been seen that the difference observed between the healthy and cancer children in terms of impulsivity, lack of self-confidenceinsufficiency, worries and anger-aggression is not meaningful $(p>0.05)$, the difference observed in terms of shyness-timidity is meaningful $(p<0.05)$.

Within the direction of the attained findings; the following issues could be suggested,

Self-expression of the children should be ensured with methods in convenience to their characteristics of age and development,

Child drawings should be repeated in different times,

$>\quad$ When the lack of stimulus of the ill children is taken into consideration, the activities that could be applied in the hospital environment should be planned,

$>\quad$ Bedside support applications giving opportunity for the children to express their feelings should be extended,

Short term hospital visits should provided by the their friends for the purpose of positively contributing to the emotional developments of the children staying in hospital,

The parents of the children having inpatient treatment in the hospital should not leave their children alone as much as possible,

The health staff who care for the children in the hospital should be educated and experienced in the use of projective methods.

In the studies to be conducted afterwards; the studies regarding the comparison of the children with acute and chronic illness to the healthy children and the comparison of the emotional states of the children having inpatient treatment at hospital to their healthy peers should be carried out in a wider sample.

\section{ACKNOWLEDGEMENT}

This study was presented as an oral presentation at the $70^{\text {th }}$ International OMEP Conference 2018 in Prague.

\section{REFERENCES}

[1] World Health Organization [homepage on the Internet]. FL: International Childhood Cancer Day: 15 February 2018 , [updated 2018 Apr 5; cited 2018 Feb 15]: Available from: http://www.who.int/cancer/iccd-2018/en/.

[2] Toruner EK, Buyukgonenc L. Basic nursing approaches in child health. (Pt 21). Amasya: Goktug Publishing 2012.

[3] Atay Turan S, Isık Esenay F, Guven M. Symptoms in children with cancer chemotherapy. Journal of Current Pediatrics 2016; 14(2): 74-81.

https://doi.org/10.4274/jcp.03164

[4] Compas BE, Desjardins L, Vannatta K, Young Saleme T, Rodriguez EM, Dunn M, Bemis H, Snyder S, Gerhardt CA. Children and adolescents coping with cancer: Self-and parent reports of coping and anxiety/depression. Health Psychology 2014; 33(8): 853-61. https://doi.org/10.1037/hea0000083

[5] Durualp E, Altay N. A comparison of emotional Indicators and depressive symptom levels of school-age children with and without cancer. Journal of Pediatric Oncology Nursing 2012; 29(4): 232-9. https://doi.org/10.1177/1043454212446616

[6] Giannakopoulos G, Kazantzi M, Dimitrakaki C, Tsiantis J, Kolaitis G, Tountas. Screening for children's depression symptoms in Greece: The use of the children's depression 
inventory in a nation-wide school-based sample. European Child \& Adolescent Psychiatry 2009; 18(8): 485-92. https://doi.org/10.1007/s00787-009-0005-z

[7] Sen Beytut D, Bolısık B, Solak U, Seyfioglu U. A study of the influences of hospitalization on children through drawing as a projective method. Maltepe University Journal of Nursing Science and Art 2009; 2: 35-44.

[8] Koçkar C, Gurol A. Anxiety, aggression and self-esteem analysis through pictures in children with cancer. Florence Nightingale Journal of Nursing 2013; 21(1): 33-9.

[9] Nazari B, Bakhshi S, Kaboudi M, Dehghan F, Ziapour A, Montazeri N. A comparison of quality of life, anxiety and depression in children with cancer and healthy children, Kermanshah-Iran. International Journal of Pediatrics 2017; 5(7): 5305-14.

[10] Toros F, Tot S, Duzovalı O. Depression and anxiety levels of parents and children with chronic Illness. Journal of Clinical Psychiatry 2002; 5(4): 240-7.

[11] Baykoç N. Children and young in hospital. (Pt 2). $1^{\text {st }}$ ed. Ankara: Gazi Bookstore 2006.

[12] Basbakkal Z, Sonmez S, Celasin NS, Esenay F. Determination of behavioral reactions of a child of 3-6 ages group to be hospitalized due to an acute illness. International Journal of Human Sciences 2010; 7(1): 456-68.

[13] Durualp E, Kara FN, Yılmaz V, Alaybeyoglu K. Comparison of life qualities according to the views of children and parents with and without chronic disease. Journal of Ankara University Faculty of Medicine 2010; 63(2): 55-63.

[14] Yavuzer H. Recognition of children with pictures. Istanbul: Remzi Bookstore 2015.

[15] Tiels AH, Alen PJ. Listen to them draw: screening children in primarycare throught to use of human figüre drawings. Pediatric Nursing 2005; 31(4): 320-7.

[16] Wong DL. Whalet \& Wong's nursingcare of infantand children. 6th ed. St. Lois-Missouri: Mosby Inc.; 1999.

[17] Matsuri $N$. Use of the drawing tecnique in nursing assessment. JSPN 2005; 10(4): 191-5. https://doi.org/10.1111/j.1744-6155.2005.00032.x

[18] Maureen V. Children's drawings of human figure. Lawrence; 1993.

[19] Johnson BH. Children's drawings as a projective tecnique. Pediatric Nursing 1990; 16(1): 11-7.

[20] Evans W, Reilly J. Drawings as a method of programme evaluation and communication with school age children. Journal of Extension 1996; 34(6): 1-9.

[21] Malchiodi CA. Using drawing as intervention with traumatized children. Trauma and Loss: Research and Interventions 2001; 1(1): 21-8.

[22] Driessnack M. Children's drawings as facilitators of comminication: A meta-analysis. Journal of Pediatric Nursing $2005 ; 20(6): 415-23$

https://doi.org/10.1016/j.pedn.2005.03.011
[23] Koppitz EM. Psychological evaluation of children's human figüre drawings. New York: Grune \& Strtton Comp. 1968.

[24] Koppitz EM. Psychological evaluation of human figüre drawings by middle school pupils. New York: Allynand Bacon Comp. 1984.

[25] Impulsiveness [homepage on the Internet]. Öztürk M, FL: Impulsiveness, [updated 2017 Sep 15; cited 2014 Dec 2]: Available from: http://www.mucahitozturk.com/durtusellik/.

[26] Cihangir N, KIlıcarslan Toruner E. Determination of emotional conditions of school age children with chronic and acute diseases by means of human figüre drawings. Journal of Hacettepe University School of Nursing 2007; 14: 1-8.

[27] Insecurity [homepage on the Internet]. Göka E, FL: Insecurity, [updated 2017 Sep 15; cited 2016]: Available from: http://filozof.net/Turkce/psikoloji/690-psikolojideguvensizlik-duygusu-nedir-guvensizlik-guven-ve-guvensizlikduygusu-serap-duygulu-cocukta-guvensizlik-duygusu-hissitanimi.html.

[28] Cavusoglu H. Child health nursing. 9th ed. (Pt 8). Ankara: Sistem Ofset Printing House 2008.

[29] Boekaerts M, Roder I. Stress, coping, and adjustment in children with a chronic disease: a review of the literature. Disability Rehabilitation 1999; 21(7): 311-37. https://doi.org/10.1080/096382899297576

[30] Saday Duman N. Cancer in children, concept of death and grief. Acta Oncologica Turcica 2014; 47(2): 26-30. https://doi.org/10.5505/aot.2014.84803

[31] Sezgin S, Ekinci M, Okanlı A. Psychosocial problems lifes the children with cancer and nursing approachs. O.M.Ü. Medical Journal 2007; 24(3): 107-12.

[32] Lewis C, Knopf D, Chastain Lorber K. Patient, parent, and physician perspectives on pediatric oncology rounds. The Journal of Pediatrics 1988; 112(3): 378-84.

https://doi.org/10.1016/S0022-3476(88)80316-0

[33] Gokler B. Child, family and physician against the deadly disease. Journal of Contribution Pediatrics 1996; 5: 919-24.

[34] Westbom L. Well-being of children with chronic illness. A population-based study in a Swedish primary care district. Acta Paediatrica 1992; 81(8): 625-9. https://doi.org/10.1111/j.1651-2227.1992.tb12314.x

[35] Yıldız Bıcakcı M, Durualp E. Social and emotional development in children. In: Neriman Aral editor. Child development. Eskisehir: Anadolu University Open Education Faculty Publications 2017; pp. 128-57.

[36] Sahin $H$. The effectiveness of the anger management program of decreasing aggressive behaviours.Turkish Psychological Counseling and Guidance Association 2006: 26(3): 47-62. 